\title{
Cartaphilus
}

Revista de investigación y crítica estética

\section{EL MONO DE HEIDELBERG \\ O LA ANTORCHA DEL LATÍN}

HEIDELBERG'S MONKEY

OR LATIN'S TORCH

\section{ANTONIO MAURIZ}

El mono de Heidelberg, la obra que aquí nos complace presentar, no contiene simplemente un cuento. El mono de Heidelberg es, además, portador de una Ilama. Al igual que, hoy en día, durante la celebración de los Juegos Olímpicos, el portador de la llama olímpica se encarga de llevar la antorcha que reúne en sí algunos de los valores más representativos de la humanidad, el presente cuento porta, en pleno siglo XXI, la antorcha de la lengua latina y de todos los valores asociados tanto a ella como a su milenaria literatura. Se halla, por tanto, al cabo de la tradición de la literatura escrita en latín, que en él se condensa.

No parece cómodo estar situado al extremo de los siglos, sobre todo si se considera que, en ese prolongado devenir, la lengua latina ha dejado de tener, en buena parte, el uso vivo mayoritario del que gozó en épocas precedentes, al punto de que la creación literaria en lengua latina resulte hoy, al lector no especializado, cuando menos una rareza, preciosa, mas con todo una rareza. $\mathrm{Y}$, por otra parte, porque crear en latín teniendo ante sí el elevadísimo ejemplo de los autores de la literatura latina de todos los tiempos -cuyo quehacer, recordémoslo, se extiende a lo largo de más de dos mil años- semeja un desafío literario de enormes proporciones.

Sin embargo, Michael von Albrecht, el autor de esta obra, ha sabido estar a la altura de este reto y ha tornado en ventajas lo que en principio parecían obstáculos. Al acabar la lectura de El mono de Heidelberg, el lector tiene la impresión de que el autor ha conseguido no solo sortear los peligros que ante él se cernían, sino también alumbrarse un espacio nuevo sobre el que erigir esta magnífica joya de la creación literaria neolatina. 
Si los autores pioneros de la literatura latina tuvieron que afrontar la dura tarea de bregar con el latín para moldearlo y darle forma literaria sin referentes previos en su propia lengua, los autores últimos, como Michael von Albrecht, se hallan, más de dos mil años después, ante la no menos compleja labor de descubrir nuevas formas de expresión o actualizar novedosamente las antiguas cuando ya el campo literario latino ha producido frutos tan exquisitos como abundantes. Pese a esa diferencia, en el presente cuento se percibe la misma pasión ante el descubrimiento de un nuevo matiz lingüístico que debió de sentir, por ejemplo, Ennio al trasladar el hexámetro desde la lengua griega a la latina o Lucrecio al crear una lengua poética de carácter filosófico o Catón al plasmar por primera vez en latín una prosa de verdadera calidad. Esa misma llama alumbra aquí con toda su fuerza, inalterada e indesmayable más de dos mil años más tarde. La centelleante y combativa conciencia de los pioneros de estar fundando una tradición en tiempos duros, sin referencias, cuando la lengua latina era todavía un simple balbuceo en busca de su plena expresión, aparece de nuevo aquí, con renovada ilusión y renovada lucha, metamorfoseada en conciencia de estar no solo participando creativamente en dicha tradición, sino también de estar conservándola y legándola a los futuros en tiempos igualmente ariscos, poco propicios para la expresión literaria en latín. Con el convencimiento, igualmente romano, de que la posteridad se habrá de imponer sobre lo efímero e incluso banal de las circunstancias actuales. Pues este libro es, en efecto, un triunfo sobre las triviales modas literarias de hoy en día.

Bajo esta perspectiva, El mono de Heidelberg es como un tesoro lingüístico, lleno de gemas y piedras preciosas de un valor incalculable, que aguardan a que el lector las descubra para resplandecer con toda su fuerza. Por sacarle brillo a una de sus más relumbrantes alhajas de la lengua, podemos hacer mención del uso de neologismos latinos, uno de los recursos más sorprendentes del cuento: términos como machinae computatrices -ordenadores- o machinae mulctrices ordeñadoras- contribuyen no solo a modernizar la vieja lengua latina, adaptándola a las nuevas realidades tecnológicas contemporáneas, sino que se hallan imbuidos de una fuerte intención literaria en la que se desvela, cómicamente, el desfase entre la perspectiva antigua y la actual. Este propósito se ve con mayor claridad en el empleo de circunloquios destinados a describir ciertos objetos del mundo moderno para los cuales el latín de época clásica no disponía de equivalente: así los coches son foetidi daemones quattuor rotis praediti -demonios malolientes provistos de cuatro ruedas-, el tren es una ex longissimis erucis, quae ferratis per humum viis serpunt -una de aquellas larguísimas orugas que serpean por vías de hierro dispuestas sobre el suelo- y el televisor es una cista quadam ex qua tremula lux exibat -una caja que emitía una luz centelleante. Más allá de la intención literaria que anima tales expresiones, se observa aquí la fuerte conciencia lingüística del autor, su creativa e infatigable brega por dotar al latín, desde un punto de vista moderno, de nuevas posibilidades expresivas.

Con todo, la lucha de Michael von Albrecht encubre un propósito adicional: tender un puente entre el pasado y el presente. Resulta obvio que, desde un 
punto de vista lingüístico, el hecho de escribir hoy en latín supone, ineludiblemente, establecer un vínculo directo entre el presente y el pasado, en razón de la propia historia de la lengua latina. Pero además, si dirigimos nuestra mirada a la dimensión literaria, nos daremos cuenta de que en el presente cuento se hace muy visible también la conciencia de estar hondamente inmerso en la tradición literaria latina. A fin de cuentas, El mono de Heidelberg se propone como una continuación de El asno de oro, de Apuleyo. En este sentido, supone una renovación, en forma de cuento breve, de la novela latina de época antigua.

En efecto, Michael von Albrecht parte de las convenciones antiguas del género, las desarrolla y las explota a fondo. Como ejemplo bástenos mencionar que El mono de Heidelberg tiene el mismo protagonista que El asno de oro: Lucio, en Apuleyo metamorfoseado en asno, reaparece aquí transformado en mono por obra de una nueva metamorfosis, conservando asimismo su mirada radicalmente humana dentro de un sobrevenido cuerpo de animal. Sin embargo, a diferencia de lo que ocurre en El asno de oro, esa mirada, entre extrañada y divertida a la vista de las circunstancias humanas (como si de un Gulliver en el país de Liliput se tratase), aparece aplicada no a la realidad contemporánea al protagonista -la antigua realidad de la vida romana-, sino, gracias a la ilusión proporcionada por la ficción narrativa, a una realidad dos mil años posterior a él -la realidad moderna del siglo XX, y por extensión del siglo XXI.

Al mismo tiempo, este enorme salto temporal, enmarcado dentro del plano de la ficción, encuentra un significativo paralelismo en las diferentes perspectivas que, en el plano de la realidad, adoptan los autores de las dos narraciones. En efecto, mientras que Apuleyo aplica, en perfecta armonía, las convenciones literarias de su tiempo a la realidad de su tiempo, Michael von Albrecht ha debido aplicar, actualizándolas, las convenciones literarias antiguas a la realidad del siglo $\mathrm{XX}$, habiéndose visto obligado de este modo a efectuar un arriesgado salto en el tiempo.

Este es, sin duda, uno de los grandes méritos de El mono de Heidelberg. Gracias a ello, la observación de la realidad moderna con los ojos antiguos del mono es inagotable fuente de crítica social (la destrucción de la naturaleza, el cambio climático, los desmanes de la sociedad de consumo, etc.) y de comicidad que el lector actual agradece continuamente. Sin embargo, lo que este hecho tiene de principal es que, gracias a ello, el presente cuento se constituye en puente entre lo antiguo y lo moderno. De ese modo, El mono de Heidelberg enraíza, aparte de en las convenciones literarias del género, en los valores asociados a la literatura latina, en una visión profundamente humanista del mundo, además de establecer, a la vez, un hondo y complejo diálogo no solo con Apuleyo, sino con otros muchos autores antiguos e incluso posteriores (patente prueba de lo cual es la intertextualidad que subyace a muchos de los pasajes del texto, que remiten a Platón, César, Virgilio, etc.). Bajo esta óptica, esta obra es como un guía que conduce al lector (como un Virgilio a su Dante) y lo introduce, con paso firme y sabio, en los misterios ocultos de nuestro pasado cultural, en 
los orígenes de nuestro pensamiento, en suma: en el sustancioso meollo de nuestra existencia.

Esta es, desde luego, una de las grandes ventajas que ofrece la creación literaria en latín. No obstante, no es la única. Quien hoy en día se aventura a escribir en latín no solo tiene acceso al pasado, sino que dispone de la posibilidad de inscribirse en el futuro. Escribir en latín supone un doble movimiento temporal desde el presente: hacia el ayer, pero también hacia el mañana. El creador en latín se halla muy lejos de dejarse arrastrar por las modas del presente, ya lingüísticas ya literarias. Su mira se está puesta en el futuro. Y con razón, porque el latín es la lengua de la posteridad. Si el latín ha sobrevivido más de dos mil años, si ha sobrevivido incluso al hecho de que haya dejado de ser una lengua hablada, si pese a esto sigue viva, ello significa que es inmortal. Que es la lengua que, con el paso del tiempo, cuando otras hayan caído en el olvido, seguirá manteniéndose incólume, sin menoscabo, como lo ha venido haciendo hasta ahora. En El mono de Heidelberg resulta muy palpable esta convicción. Aunque sea una obra rabiosamente enraizado en la actualidad, su meta no es, en realidad, el presente, sino el futuro, la posteridad. Lo que en él se nos cuenta es, como diría Horacio, más imperecedero que el bronce.

Desde esta óptica, es fácil entender por qué Michael von Albrecht ha decidido emplear la lengua latina a la hora de afrontar la creación literaria: poder reunir, en una única obra, las tres instancias temporales, pasado, presente y futuro, significa, tanto para él como autor, como para sus lectores, presentes y futuros, el inigualable placer de participar de la atemporalidad. Ese privilegio emana única y exclusivamente del empleo del latín. Ninguna otra lengua podría haberlo proporcionado.

Por otro lado, por si ello fuera poco, nos atrevemos a afirmar que el hecho de que Michael von Albrecht haya optado por escribir en latín supone, simple y llanamente, una reivindicación de la belleza. En unos tiempos en que la utilidad económica y material se ha hecho omnipresente en cualquier actividad o quehacer humano, escribir en latín constituye un acto verdaderamente poético, casi diríamos que romántico, si no fuera porque también los romanos supieron, mucho antes que los románticos, valorar la utilidad de lo inmaterial, de aquello que, como la literatura, la buena literatura, no ofrece un inmediato provecho material.

Pero no se trata simplemente de que escribir en latín sea bello en sí mismo, sino de que la lengua latina es un constante manantial de belleza. No es este motivo menor por el cual se mantiene viva. El placer estético que la lengua latina proporciona a sus lectores es difícil de encontrar en otra lengua: la concisión, la precisión, la sonoridad de esta lengua son inigualables, por solamente citar algunas de sus más evidentes y más ensalzadas virtudes. $Y$, en manos de un maestro de la lengua y un autor literario de la talla de Michael von Albrecht, estas virtudes alcanzan cotas verdaderamente muy elevadas, difíciles de alcanzar. En el presente cuento es posible disfrutar, en grandísima medida, de todas ellas. 
Michael von Albrecht se revela aquí, pues, como una de las cabezas visibles de la Latinitas viva, el movimiento que propugna el ideal de defensa del latín como una lengua viva, en una época en que muchos la dan por muerta. Sin embargo, esta edición bilingüe, en latín y castellano, de El mono de Heidelberg es muestra clara de que esos muchos están equivocados. No solo porque la mera existencia de la edición desmiente tal hecho, sino porque muchos son precisamente los que, por el contrario, con su apoyo editorial ayudan al maestro de Heidelberg, en responsabilidad compartida, a portar el peso, nada liviano, de la antorcha del latín.

Esta edición bilingüe, en latín y castellano, de El mono de Heidelberg es el último fruto del compromiso de la Universidad de Murcia con la lengua y la literatura latinas en general y con la obra, tanto académica como literaria, de Michael von Albrecht en particular. Su colaboración editorial con el maestro de Heidelberg abarca ya una década y, previos a este, ha dado beneficios tan inestimables como la edición en castellano de cinco de sus más grandes estudios académicos sobre literatura latina, ya clásicos de la filología clásica: Virgilio (2012), Grandes maestros de la prosa latina (2013), Ovidio (2014), Poetas de la libertad: de Lucrecio y Catulo a Ovidio (2016) y Séneca o el arte de la vida (2019). Alma mater de este proyecto editorial, y también portadora de su propia antorcha del latín, ha sido la profesora Francisca Moya del Baño, catedrática de latín de la Universidad de Murcia, cuyo empeño y pasión, indesmayables a lo largo de todo este tiempo, han sido fundamentales para que tanto el cuento presente como las demás obras mencionadas hayan podido ver la luz en nuestra lengua y llegar a miles de lectores en castellano. Ahora Vicente Cervera Salinas, magnífico poeta e igualmente profesor de la Universidad de Murcia, abre las puertas de la revista Cartaphilus, que con tan sabios propósitos él mismo dirige, para acoger El mono de Heidelberg, como antes tan amablemente había abierto las del sello Signos de Editum para dar bienvenida a varios de los estudios mencionados anteriormente.

A todos ellos, tanto al autor de la obra, el profesor Michael von Albrecht, como a los promotores de la presente edición, la Universidad de Murcia y los profesores Francisca Moya del Baño y Vicente Cervera Salinas, queremos expresar nuestro más caluroso agradecimiento por mantener en alto, bien visible, la antorcha del latín. 